\title{
Confirmatory Factor Analysis of Service Quality Dimensions in Healthcare
}

\author{
Dr. Rupa Rathee ${ }^{1}$, Pallavi Rajain ${ }^{2}$, Dr. Isha ${ }^{3}$ \\ ${ }^{1}$ Assistant Professor, Department of Management Studies, Deenbandhu Chhotu Ram University of Science and Technology, Murthal \\ (Sonepat), India \\ ${ }^{2}$ Research Scholar, Department of Management Studies, Deenbandhu Chhotu Ram University of Science and Technology, Murthal \\ (Sonepat), India
}

${ }^{3}$ Physiotherapist, Civil Hospital, Gurgaon, India

\begin{abstract}
Service quality has been defined as the outcome of an evaluation process where the consumer compares his expectations with the service he has received or the difference between expected service and perceived service. In today's increasing competitive atmosphere providing service quality is important for any service industry. Health care services have a distinct position among other services due to highly involving and risky nature of services and the general lack of expertise possessed by consumers. In this study, five service quality dimensions are used i.e. tangibility, reliability, assurance, responsiveness and empathy. The 22 items SERVQUAL scale based on gap model proposed by Parasuraman, Zeithmal and Berry was applied. A sample size of 200 was taken using quota sampling. Confirmatory Factor Analysis was employed to find the fit of the model and also a comparison between the expectations and perceptions of government and private hospitals was made using mean values with the application of SPSS and AMOS software packages. Through the analysis it was found that the SERVQUAL model is fit for the present study. It was also clear from the mean values that people had higher expectations from private hospitals.
\end{abstract}

Keywords: CFA, Government hospitals, Private hospitals, Service quality, SERVQUAL.

\section{Introduction}

Service quality has been defined as the outcome of an evaluation process where the consumer compares his expectations with the service he has received or the difference between expected service and perceived service. Services have been categorized as being either consumer services or professional services. Customers evaluate service quality both on the outcomes of the service and the process of service delivery. Health care services have a distinct position among other services due to highly involving and risky nature of services and the general lack of expertise possessed by consumers. This makes conceptualizing and measuring customer satisfaction and service quality in health care settings more important and at the same time more complex. To maintain and improve the quality of health care services, besides relying on clinical and economic criteria, administrators should utilize the feedback through patient perception of care surveys. Adopting the marketing concept to health care, requires that the providers be consumer oriented, and concern themselves with the satisfaction of their patients. As hospitals and other health care providers begin to implement better and sophisticated patient's surveys, they will understand the strengths and weaknesses of their organizations from the patients' point of view.A better understanding of how consumers evaluate the quality of health care will help administrators and service providers, in determining and improving weaker aspects of their health care delivery system. With continuous monitoring of patient's perceptions and improvements based on patient feedback, quality of care and patient satisfaction will improve. Keeping pace with current technological advance, people today are choosing a new approach to healthcare services, they are well informed and eager to take responsibility for their own health. Therefore, the consumers of healthcare services have exceptionally higher expectations and demand a high level of accuracy, reliability, responsiveness, and empathy. In short, they demand overall better healthcare services than in the past. They are also becoming more critical of the quality of healthcare services they are provided with.

\section{Review of Literature}

Several researchers have studied various aspects of service quality in healthcare industry. Rao et al. (2006) studied patients' perceptions of quality at public health facilities. The authors found that public health facilities are slightly better than neutral. Doctor'sbehaviour has the largest effect on general patient satisfaction followed by the medicine availability [1].Similarly, Caha (2007) researched patients' perception towards the private hospital. The results indicated that private hospitals were more due to believe that they provide qualitative health services. The lack of physical and human capacities of these hospitals seems to be the main reasons behind the quality of the service [2].Anand and Sinha (2008) investigated the need of cognitive intermediation. The results showed that relatively higher level of health worker visit, adjusted segment was characterized by higher literacy level.Level of public facilities utilization is higher in this segment [3].Arasli et al.(2008) developed and compared determinants of service quality in public and private hospitals of Northern Cyprus. The study identified six factors regarding the service quality which include empathy, giving priority to the inpatients needs, relationships between staff and patients, professionalism of staff, food and the physical environment [4].Padma et al. (2009) studied the two instruments for measuring the dimensions of hospital service quality. It was found that one each from the perspective of patients and 


\section{International Journal of Science and Research (IJSR) \\ ISSN (Online): 2319-7064 \\ Index Copernicus Value (2013): 6.14 | Impact Factor (2015): 6.391}

attendants are proposed [5].Singh (2010) checked overall condition of healthcare services in public hospitals.Patients were found to be dissatisfied with the doctor's check-ups, mostly patient were found dissatisfied with the recovery since admission in the hospital.Majority patients did not lodge complaints against the behaviour of staff \& quality of services [6].Narichiti (2010) revealed the perception of doctors and nursing staff in case of Government General Hospital.There was perceptible gap in the minds of doctors $\&$ nursing staff on the dimension of service expected \& received.The gap is thin in case of doctors \& nursing staff [7].Kumaraswamy (2012) measured service quality in corporate and non-corporate health care centers. The analysis revealed that the important service quality factors in health care centers are physician behaviour, supportive staff, atmospherics and operational performance.The perception on service quality factors in health care centers has a significant and positive impact on the patients' perception on the overall performance of the health care centre [8].AlBorie and Damanhouri (2013) provided guidelines to the Saudi Arabian health service reorganization. The results showed that sex, education, income and occupation were statistically significant in influencing inpatients' satisfaction, and all the null hypotheses were rejected. Only inpatient age was not significant [9].Abuosi and Atinga (2013) assessed patients' hospital service quality perceptions and expectation using SERVQUAL and outlined the distinct concepts used to assess patient perceptions.Service quality perception was rated lower than expectations for all variables. The mean difference between perceptions and expectations was statistically significant [10].Markovic (2014) assessed the impact of service quality on customer satisfaction in the healthcare sector. The analysis revealed that patients perceived a rather satisfactory level of health care quality across all SERVQUAL dimensions. This study confirms the usefulness of the SERVQUAL model in terms of its reliability and validity for measuring quality in the health care sector [11].Kayral (2014) studied perception of the quality of services provided in the field of health by those who receive them was compared according to different types of hospitals providing such service.It can be said that public general branch hospitals are perceived as quality at the same level with private hospitals and even they reach higher levels of patient satisfaction. It is seen that public hospitals are still behind private hospitals in terms of physical quality [12].Aiswarya and Rajeswari (2015) examined the patients' perception of service quality.It was found that reliability, empathy and responsiveness were considered as contributing factors of patients' satisfaction.High expectation and perception for hospitals can be related patients' confidence and trust on services provided by hospitals [13]. Rathee et al. (2015) used gap analysis to find the gaps between expected and performed service in private hospitals of NCR. They found that maximum gaps existed in dimensions of reliability and empathy and also it was seen that though the males and females differed in their perception about service quality of hospitals they had similar views regarding expectations [14]. Pai and Chary (2016) designed a conceptual framework for measuring patient perceived hospital service quality (HSQ). An instrument for measuring HSQ dimensions was developed and compared with other service quality measuring instruments. The latest dimensions were in line with previous studies, but a relationship dimension was added [15].Shabbir et al. (2016) explored the relationship between healthcare perceived service quality (HCSQ) and patient loyalty.Findings indicated that healthcare perceived service quality had a significant positive effect on patients' loyalty. Patient satisfaction mediated the relationship between HCSQ and patient loyalty. Findings stated that there was a significant difference between HCSQ which is perceived by the patients of both public and private sector hospitals [16]. Rezaei et al. (2016) assessed the quality of service in educational hospitals affiliated with Kermanshah University of Medical Sciences from the perspective of patients. The quality was assessed by the SERVQUAL questionnaire with five dimensions. The patients ranked responsiveness as the most important dimension of the quality of healthcare [17].

\section{Objectives}

1) To test the existing service quality model using confirmatory factor analysis.

2) To compare the perception and expectation of customers regarding service quality in public and private sector hospitals.

\section{Research Methodology}

The study is based mainly on the primary data collected from the patients of private hospitals of NCR region, named Pushpanjli hospital, Metro Heart \& Cancer Institute, Columbia Asia, Saraswati hospital and Government hospitals i.e. Civil hospital and ESIC hospital with the help of a well drafted, pre-tested, and structured questionnaire SERVQUAL based on 22 statements given by Parasuraman, Zeithmal and Berry (1988) [18]. Factors which determine the service satisfaction level were studied with the help of Five point LIKERT/scale ranging from strongly disagree to strongly agree. A sample of 200 was taken using quota sampling with 100 males and 100 females. SPSS version 23 was used to apply mean and AMOS version 21 was used for Confirmatory Factor Analysis. Secondary data related to previous studies has been obtained from authentic sources like books, magazines and journals.

\section{Statements for perception regarding service quality}

\section{Tangibility}

T1 Does the hospital have proper treatment modality? T2 Are the hospital physical facilities visually appealing?

T3 Are the hospital reception desk employees neat appearing?

T4 Are the physical facilities associated with the service (Registration; helping desk) visually appealing?

\section{Reliability}

RL1 When the hospital promises to do something by a certain time it does so?

RL2 When you have a problem, the Hospital is sympathetic and reassuring?

RL3 Does the hospital perform the service right the first time

RL4 Does the hospital provide its service at the time it promises to do so?

RL5 Does the hospital MRD insist on error free records?

Responsiveness

RS1 Do the employees in the hospital tell you exactly when 


\section{International Journal of Science and Research (IJSR) \\ ISSN (Online): 2319-7064}

Index Copernicus Value (2013): 6.14 | Impact Factor (2015): 6.391

services will be performed?

RS2 Do the employees of the hospital give you prompt services?

RS3 Are employees in the hospital always willing to help you?

RS4 Employees in the hospital are never too busy to respond to your request?

\section{Assurance}

A1 Does the behavior of employees in the hospital instill trust in you?

A2 Do you feel safe in your treatment in the hospital?

A3 Are the employees in the hospital area polite with you?

A4 Do the employees in the hospital have the knowledge to answer your question?

Empathy

E1 Does the hospital give you Individual attention?

E2 Does the hospital have employees who give you personal attention?

E3 Does the hospital understand your specific need?

E4 Does the hospital have your best interest at heart?

E5 Does the hospital have operating hours convenient to all its customer?
E3 The employees of hospital will understand the specific need of their customers

E4 Hospital will have their customer's best interest at heart E5 Hospital will have operating hours convenient to all their customers

\section{Analysis and Findings}

In order to test the reliability of the scale Cronbach's alpha was calculated which was found to be 0.96 which shows the high reliability of the scale.

A confirmatory factor analysis (CFA) using AMOS 21 was conducted to test the measurement model. Figure 1 shows a measurement model of the five dimensions under service quality. Construct "Tangibility (T)," "Reliability (RL)," "Responsiveness (RS)," "Assurance (A)" and "Empathy (E)" are indicated by four, five, four, four and five indicators items, respectively, thus five constructs are measured by 22 measured indictor variables.

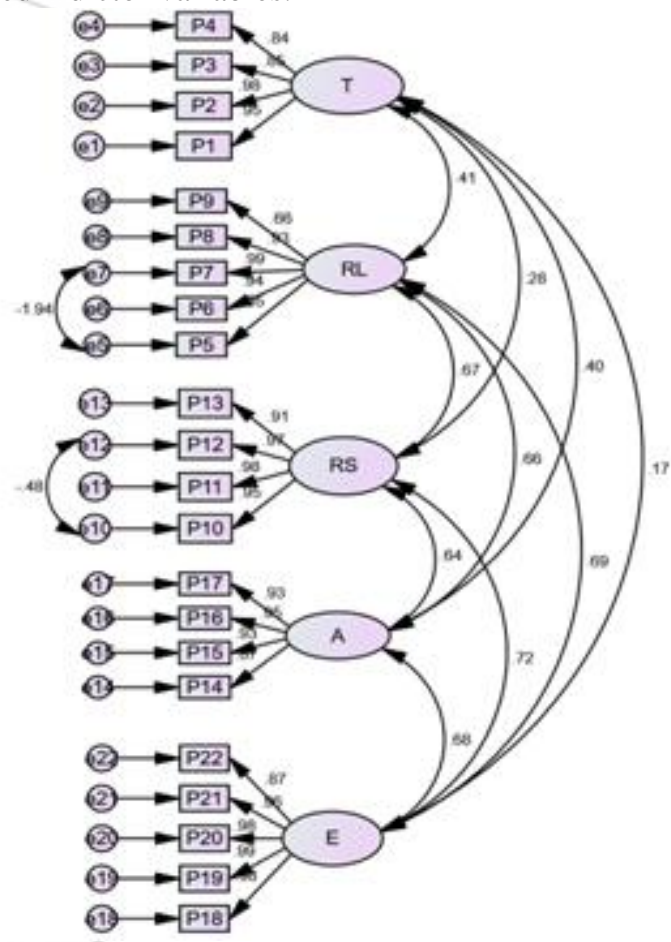

Figure 1: CFA Model

Statements for expectation regarding service quality

\section{Tangibility}

T1 Multi-Specialty hospital have modern looking equipment?

T2 The physical facility at hospital will be visually appealing

T3 Employees at Multi-specialty hospital will be neat appearing

T4 Physical facilities associated with the service such as pamphlets or statements will be visually appealing to a hospital

\section{Reliability}

RL1 When hospital promises to do something by a certain time they do

RL2 When a customer has a problem, hospital will be sympathetic and reassuring

RL3 Hospital will perform the service right the first time

RL4 Hospital will provide the service at the time they promise to do so

RL5 Hospital will insist on error free record

\section{Responsiveness}

RS1 Employees of hospital will tell customers exactly when services be performed

RS2 Employees of hospital will give prompt services to customer

RS3 Employees of hospital will always be willing to help customers

RS4 Employees of hospital will never be too busy to respond to customer requests

\section{Assurance}

A1 The Behavior of employees in hospital will instill trust in customer

A2 Customer of hospital will feel safe in transactions

A3 Employees of hospital will be polite with customer

A4 Employees of hospital will have the knowledge to answer customer's questions

\section{Empathy}

E1 Hospital will give customers individual attention

E2 Hospital will have employees who give customer

personal attention 


\section{International Journal of Science and Research (IJSR) \\ ISSN (Online): 2319-7064}

Index Copernicus Value (2013): 6.14 | Impact Factor (2015): 6.391

Table 1: Confirmatory Factor Analysis

\begin{tabular}{|c|c|c|c|c|c|}
\hline Variable & CFI & GFI & TLI & NFI & RMSEA \\
\hline Measurement model & .89 & .81 & .87 & .87 & .14 \\
\hline
\end{tabular}

Source: Survey by authors

The model fit indices like the Comparative Fit Index (CFI), the Goodness of Fit Index (GFI), Normed Fit Index (NFI), Tucker Lewis Index (TLI) and root mean square of error approximation (RMSEA) were selected to judge the model fit. In order to obtain an acceptable fit with data, CFI, GFI, NFI and TLI should be around 0.9 and the RMSEA value must be lower than 0.08. As seen from table 1 the values of CFI, GFI, TLI, NFI and RMSEA are $.89, .81, .87, .87$ and .14 are very close to the threshold values, thus representing an acceptable model fit.

Table 2 shows that the values of perception were higher for private hospitals as compared to government hospitals except for the dimension of tangibility where the reverse was true. The largest difference was for whether the hospital understands the patient's specific needs and the lowest difference was for hospital reception desk employees are neat appearing. It can also be seen that the gaps were higher for perceptions as compared to expectations showing that the level of perceptions are much similar for both kind of hospitals compared to expectations.

Table 2: Service Quality perception

\begin{tabular}{|l|c|c|c|}
\hline Statements & Govt. Hospital & Private Hospital & Difference \\
\hline T1 & 3.91 & 3.68 & 0.23 \\
\hline T2 & 3.93 & 3.73 & 0.20 \\
\hline T3 & 3.95 & 3.78 & 0.17 \\
\hline T4 & 3.95 & 3.75 & 0.20 \\
\hline RL1 & 3.26 & 3.68 & -0.42 \\
\hline RL2 & 3.26 & 3.68 & -0.42 \\
\hline RL3 & 3.29 & 3.74 & -0.45 \\
\hline RL4 & 3.31 & 3.76 & -0.45 \\
\hline RL5 & 3.47 & 3.73 & -0.26 \\
\hline RS1 & 3.15 & 3.67 & -0.52 \\
\hline RS2 & 3.12 & 3.72 & -0.60 \\
\hline RS3 & 3.12 & 3.76 & -0.64 \\
\hline RS4 & 3.11 & 3.71 & -0.60 \\
\hline A1 & 3.30 & 3.71 & -0.41 \\
\hline A2 & 3.46 & 3.75 & -0.29 \\
\hline A3 & 3.37 & 3.78 & -0.41 \\
\hline A4 & 3.38 & 3.73 & -0.35 \\
\hline E1 & 2.96 & 3.73 & -0.77 \\
\hline E2 & 2.95 & 3.75 & -0.80 \\
\hline E3 & 2.93 & 3.74 & -0.81 \\
\hline E4 & 2.93 & 3.73 & -0.80 \\
\hline E5 & 2.89 & 3.68 & -0.79 \\
\hline
\end{tabular}

Source: Survey by authors

Table 3: Service Quality expectations

\begin{tabular}{|l|c|c|c|}
\hline Statements & Govt. Hospital & Private Hospital & Difference \\
\hline T1 & 3.62 & 3.88 & -0.26 \\
\hline T2 & 3.76 & 4.00 & -0.24 \\
\hline T3 & 3.80 & 4.01 & -0.21 \\
\hline T4 & 3.83 & 4.01 & -0.18 \\
\hline RL1 & 3.86 & 4.03 & -0.17 \\
\hline RL2 & 3.83 & 4.03 & -0.20 \\
\hline RL3 & 3.84 & 4.03 & -0.19 \\
\hline RL4 & 3.84 & 4.01 & -0.17 \\
\hline RL5 & 3.84 & 4.00 & -0.16 \\
\hline RS1 & 3.81 & 4.00 & -0.19 \\
\hline RS2 & 3.82 & 3.99 & -0.17 \\
\hline RS3 & 3.81 & 4.00 & -0.19 \\
\hline RS4 & 3.83 & 4.02 & -0.19 \\
\hline A1 & 3.92 & 4.03 & -0.11 \\
\hline A2 & 3.90 & 4.03 & -0.13 \\
\hline A3 & 3.90 & 4.03 & -0.13 \\
\hline A4 & 3.89 & 4.03 & -0.14 \\
\hline E1 & 3.87 & 4.03 & -0.16 \\
\hline E2 & 3.84 & 4.01 & -0.17 \\
\hline E3 & 3.84 & 4.02 & -0.18 \\
\hline E4 & 3.84 & 4.01 & -0.17 \\
\hline E5 & 3.84 & 4.02 & -0.18 \\
\hline S & & &
\end{tabular}

Source: Survey by authors

Table 3 shows that the values for expectation were higher for private hospitals. It also shows that the difference in mean values for service quality expectation in government and private sector hospitals was higher for certain dimensions. The difference was largest for multi-specialty hospital have modern looking equipment and lowest for the statement that behaviour of employees in hospital will instil trust in customer.

\section{Conclusion}

The overall fit of the measurement model was determined by confirmatory factor analysis. To evaluate the measurement model it was necessary to use a variety of "goodness of fit" indices. Accordingly, the assessment of the model fit was based on the criteria such as CFI, TLI, NFI and RMSEA. All of the statistical values of the final measurement model indicated that the model fitted well in representing the data.

The comparison between government and private hospitals for expectations and perceptions showed that customers had higher expectations from private hospitals and also the perceptions of private hospitals was higher. It was also found that the difference between perceptions was higher for the two kinds of hospitals compared to the expectations which shows that the level of perceptions is much similar for both kind of hospitals compared to expectations.

It can be concluded that in present times the healthcare industry is in a very competitive stage with government and private hospitals trying to attract more patients. Although due to the low consultation fees for government hospitals, the poor population opts for these as the higher priced hospitals are much beyond their reach. The service quality dimensions are much more important for the middle and higher income groups.

\section{Suggestions}

\section{Volume 5 Issue 5, May 2016} www.ijsr.net 


\section{International Journal of Science and Research (IJSR) \\ ISSN (Online): 2319-7064 \\ Index Copernicus Value (2013): 6.14 | Impact Factor (2015): 6.391}

1) The findings showed that people perceived that private hospitals better understood patient's specific needs. Therefore, private hospitals can use this dimension as their unique selling point.

2) It was also found that the both the perception and expectation were higher for private hospitalsregarding promptness of services and response to requests so an effort needs to be made by government hospitals to improve their standards on these aspects.

3) As it was found that there was a large gap in expectation for multi-specialty hospital having modern looking equipment which shows that governments hospitals are expected to make availablemodern looking equipment. Hence they need to improve their position regarding this dimension.

4) The analysis showed that the private hospitals were expected to be more visually appealing and neat appearing compared to government hospitals which shows the lack of effort on their part regarding infrastructure. Therefore, government hospitals need to improve their image by improving infrastructural facilities.

\section{References}

[1] Rao, Dipankar, Krishna, Peters, H., David, Bandeen Roche, Karen (2006), Towards patient - Centred Health Services in India ----A scale to Measure Patient perceptions of Quality, International journal for Quality in Health care, 18 (6), 414-421.

[2] Caha, H. (2007), Service Quality in Private Hospitals in Turkey, Journal of Economic and social research, 9 (1), 55-69.

[3] Anand, S. and Sinha, R.K. (2012), Segmentation of Clients in India on the basis of reproductive health welfare index, Connecting Business \& Society, XIM, Bhubaneshwar, India.

[4] Arasli, H., Haktan Ekiz, E., \& Turan Katircioglu, S. (2008). Gearing service quality into public and private hospitals in small islands: empirical evidence from Cyprus. International Journal of health care quality Assurance, 21(1), 8-23.

[5] Padma, Panchapakesan, Rajendran Chandrasekharam, Lokachari Sai Prakash, (2009) A Conceptual Framework of Service Quality in Healthcare: Perspectives of Indian Patients and their Attendants, Benchmarking: An International Journal, 16 (2), 157191.

[6] Singh, R. (2010), Patients' Perception towards Government Hospitals in Haryana, VSRD Technical \& Non- Technical Journal, I (4), 198-206.

[7] Narichiti, V. (2010), Patient Centred Hospitals: A study to evaluate the Effectiveness of Health Care Delivery in the three selected Hospitals in Guntur District, Andhra Pradesh, India.

[8] Kumaraswamy, S. (2012), Service Quality in Health Care Centres: An Empirical Study. International Journal of Business and Social Science, 3(16), 141-150.

[9] Al-Borie, H. M., \& Sheikh Damanhouri, A. M. (2013). Patients' satisfaction of service quality in Saudi hospitals: a SERVQUAL analysis. International journal of health care quality assurance, 26(1), 20-30.
[10] Abuosi, A. A., \& Atinga, R. A. (2013). Service quality in healthcare institutions: establishing the gaps for policy action. International journal of health care quality assurance, 26(5), 481-492.

[11] Markovic, S., Loncaric, D. \& Loncaric, D. (2014), Service Quality and Customer Satisfaction in the Health Care Industry -Towards Health Tourism Market. Tourism and Hospitality Management, 20(2), 155-170.

[12] Kayral, İ.H. (2014), Perceived Service Quality in Healthcare Organizations and a Research in Ankara by Hospital Type. Journal of Ankara Studies, 2(1), 22-34.

[13] Aiswarya, S. \& Rajeswari, P.S. (2015), An analytical study of Patients' Perception on the service quality of Indian Hospitals. Research Journal of Applied Sciences, 10(4), 111-114.

[14] Rathee, R., Rajain, P., \& Isha, P. T. (2015). Health care service quality: a study of private hospitals. EXCEL International Journal of Multidisciplinary Management Studies, 5(6), 106-118.

[15]Pai, Y.P., \& Chary, S.T. (2016), Measuring patientperceived hospital service quality: a conceptual framework, International Journal of Health Care Quality Assurance, 29(3), 300 - 323.

[16] Shabbir, A., Malik, S.A., \& Malik, S.A. (2016), Measuring patients' healthcare service quality perceptions, satisfaction, and loyalty in public and private sector hospitals in Pakistan, International Journal of Quality \& Reliability Management, 33(5), $538-557$

[17] Rezaei, S., Matin, B. K., Khalil Moradi, B. B., Fallahi, M., Shokati, B., \& Saeidi, H. (2016). Measurement of Quality of Educational Hospital Services by the SERVQUAL Model: The Iranian Patients' Perspective. Electronic Physician, 8(3), 2101.

[18] Parasuraman, A., Zeithaml V., \& Berry L. (1988), SERVQUAL: A Multiple-item Scale for Measuring Consumer perceptions of Service Quality, Journal of Retailing, 64(1), 12-40.

[19] Hair, J.F. (2010), Multivariate data analysis, Kennesaw, Faculty Publications.

\section{Author Profile}

Dr. Rupa Rathee is presently working as Assistant Professor in the Department of Management Studies, DCRUST, Murthal. She has more than thirteen years of teaching experience to her credit. She has attended 15 FDPs at various prestigious institutes like IIM-Bangalore, IIM-Calcutta, IIM-Kozhikode, MDI-Gurgaon, IITM-Gwalior, JNTU-Hyderabad etc. She has contributed papers in several international conferences and national conferences. She has twelve publications to her credit in reputed international and national journals. Her area of interest are Marketing and HRM.

Pallavi Rajain is pursuing her Ph.D. from DCRUST, Murthal (India). She received her B.Tech. from Kurukshetra University and MBA from DCRUST, Murthal in 2010 and 2012, respectively. She has qualified UGC NET and worked as Project Fellow on a UGC sponsoredmajor research project on Women Entrepreneurship. She has presented papers in 17 national and international conferences. She has received "Second Best Paper Award" in International Conference held at JIMS, Rohini. She has 9 publications in National and International Journals. 